\title{
Mannheimia haemolytica İzole Edilen Pyometralı Bir Kedi Uterusunun
}

\section{Anormal Genişlemesi}

\author{
Zeynep GÜNAY UÇMAK ${ }^{1 *}$, Belgi DiREN SIĞIRCI ${ }^{2}$, Melih UÇMAK ${ }^{1}$, Ali Can ÇETiN ${ }^{1}$, Kemal METiNER², \\ Barış HALAÇ²
}

\author{
1 İstanbul Üniversitesi Veteriner Fakültesi Doğum ve Jinekoloji Anabilim Dalı, \\ 2 İstanbul Üniversitesi Veteriner Fakültesi Mikrobiyoloji Anabilim Dalı, İstanbul, Türkiye.
}

Gelis Tarihi: 28.03.2018

Kabul Tarihi: 02.07.2018

\begin{abstract}
Özet: Bu yazıda, kısırlaştırılmamış, 8 yaşında, 5 kg ağırlı̆ında olan ve çok su içme, çok idrar yapma, iştahsızlık, karında aşırı şişlik şikayetleriyle kliniğimize getirilen dişi bir tekir kedideki pyometra olgusu sunulmaktadır. Yapılan testler sonucunda viral hastalıklar yönünden negatif olduğu belirlenen kedide, lökositozun yanısıra üre ve aspartat aminotransferaz (AST) değerlerinin yüksek, albumin değerinin ise düşük olduğu saptandı. Ultrasonografik muayenede aşırı abdominal genişlemenin, pyometra nedeniyle olduğu saptandıktan sonra, sağaltım amacıyla ovariohisterektomi uygulandı. Alınan uterusun ağırlığı toplam 2.4 kg olarak ölçüldü. Pyometralı içerikten alınan örnekten mikrobiyolojik identifikasyon amacıyla yapılan ekim sonucunda, pyometra olgularında izole edildiğine dair literatür bilgiye rastlamadığımı, Mannheimia haemolytica saptandı. Sonuç olarak, sunulan bu olguda kedilerde pyometra olgularında Mannheimia haemolytica izole edilebileceği ve bu bakterinin kedinin canlı ağılığına yakın boyutlara erişebilecek büyüklükte uterus hacminde artışa sebep olabileceği vurgulanmıştır.
\end{abstract}

Anahtar kelimeler: Dişi kedi, Pyometra, Mannheimia haemolytica.

\section{An Unusual Enlargement of Pyometric Uterus of A Cat From Which Mannheimia haemolytica Was Isolated}

Abstract: A case of pyometra in sexually intact, 8 years old tabby queen cat of $5 \mathrm{~kg}$ body weight which was admitted to our clinic with the complaint of polyuria, polydypsia, lethargy and unusual abdominal extension was presented in this article. Leucocytosis, increased urea and aspartate aminotransferase (AST) and decreased albümin were determined in the queen which was free from feline viral diseases. In ultrasonographic examination, abdominal expansion was found to be due to the unusual enlargement in cornu uteries and pyometra, thus ovariohysterectomy was performed for treatment. Total uterine weight was $2.4 \mathrm{~kg}$. By microbiological examination on exudat of cornu uteries, Mannheimia haemolytica was detected which has not previously been reported to be isolated from pyometra cases. As a results of this case study, it was emphasized that Mannheimia haemolytica can be isolated in feline pyometra and can cause an increase in uterine volume close to the body weight of the queen.

Keywords: Queen, Pyometra, Mannheimia haemolytica.

\section{Giriş}

Kistik endometrial hiperplazi pyometra (CEH-P) kompleks, endometrial bezlerin kistik dilatasyonu sonucu gelişir ve endometrial hiperplazi ile purulent eksudatın uterus lümenine toplanmasıyla karakterizedir (Hollinshead ve Krekeler, 2016). Köpeklere kıyasla kedilerde daha az görülen CEH-P, acil müdahale gerektiren jinekolojik bir hastalıktır (Blendiger ve ark., 1997; Dinç, 2005). Kedilerde ortalama 7 yaşında görülmesine rağmen progesteron uygulanan genç dişi kedilerde de CEH-P şekillenebilir (Lucas ve ark., 2000). Olgular, çoğunlukla bakteriyel enfeksiyon, vaginanın normal fırsatçı florasından köken alır ve anormal endometrium dokusu bakteriyel kolonizasyon için predispozisyon sağlar (Von Reitzeinstein ve ark., 2000). Kedilerdeki pyometra vakalarının yaklaşık $\% 80$ 'ninde aerobik bakteriler izole edilmektedir ve en çok rastlanan bakteri Escherichia coli'dir (E. coli) (Holt ve ark., 2003). İzole edilen diğer bakteriler;
Streptokoklar, Stafilokoklar, Klebsiella, Pseudomonas, Proteus, ve Moraxella olarak bildirilmiştir (Agudelo, 2005; Lucas ve ark., 2000). Mannheimia haemolytica kedi, köpek ve ruminantlarda genellikle respiratörik sistem hastalıklarına, koyunlarda da meme enfeksiyonlarına sebep olan bir bakteridir (Machino ve ark., 2011; Omaleki ve ark., 2011; Singh ve ark., 2011). Mannheimia Haemolytica'dan kaynaklanan CEH-P olgularına ilişkin literatür bilgiye rastlanılmamıştır. Pyometra olgularında en sık görülen klinik belirti vajinal mukopurulent veya irinli akıntıdır fakat kapalı serviks pyometra olgularında vaginal akıntı görülmez, abdominal genişleme daha yaygındır (Agudelo, 2005). Hastalıkla ilgili nonspesifik klinik bulgular ise; iştahsızlık, kusma, halsizlik ve kilo kaybıdır (Dinç, 2005). Hastalığa ilişkin klinik belirtiler uterusun yanısıra üriner 
sisteme de yansır fakat poliüri ve polidipsi köpeklerdeki kadar sık görülmez (Agudelo, 2005).

Sunulan bu olguda, uterus hacminde aşırı artışa sebep olan bakterinin identifikasyonu yapılarak, bu bakterinin pyometra gelişimi üzerine etkileri ve operatif yolla sağaltımda dikkat edilecek hususları değerlendirmek amaçlanmıştır.

\section{Olgu}

Sekiz yaşında, kısırlaştırılmamış, $5 \mathrm{~kg}$ ağırlığında, dişi tekir kedi; çok su içme, çok idrara çıkma, iştahsızlık, karında aşırı şişlik (Şekil 1.) nedeniyle kliniğimize getirildi. Hastanın genel muayenesinde vücut sıcaklığının $38.1^{\circ} \mathrm{C}$ ve mukozalarının pembe renkte olduğu tespit edildi. Vaginal inspeksiyonda serviksten gelen herhangi bir akıntıya rastlanmadı. Hastanın hemogram bulgularında anemi saptanmadı fakat lökositoz (WBC: $109.6 \times 10^{3} / \mu \mathrm{L}$ ) tespit edildi. Biyokimyasal analiz sonucuna göre aspartat aminotransferaz (AST: $146 \mathrm{U} / \mathrm{L}$ ) ve üre $(81 \mathrm{mg} / \mathrm{dl})$ değerleri yüksek, albümin $(2.1 \mathrm{~g} / \mathrm{dl})$ değeri düşük olarak ölçüldü. Ayrıca hastanın feline infeksiyöz peritonitis (FIP), feline immun yetmezliği virusu (FIV), feline lösemi virüs (FeLV) yönünden negatif olduğu belirlendi. Transabdominal ultrasonografide; sağ ve sol kornu uterilerde ölçülebilen en yüksek çaplar sırasıyla 83.2 $\mathrm{mm}$ ve $73.3 \mathrm{~mm}$ olarak saptandı (Şekil 2).

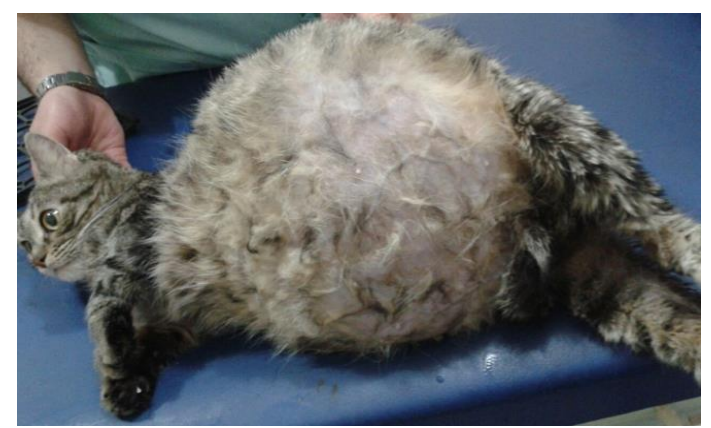

Şekil 1. Pyometra nedeniyle aşırı genişlemiş abdomen görüntüsü.

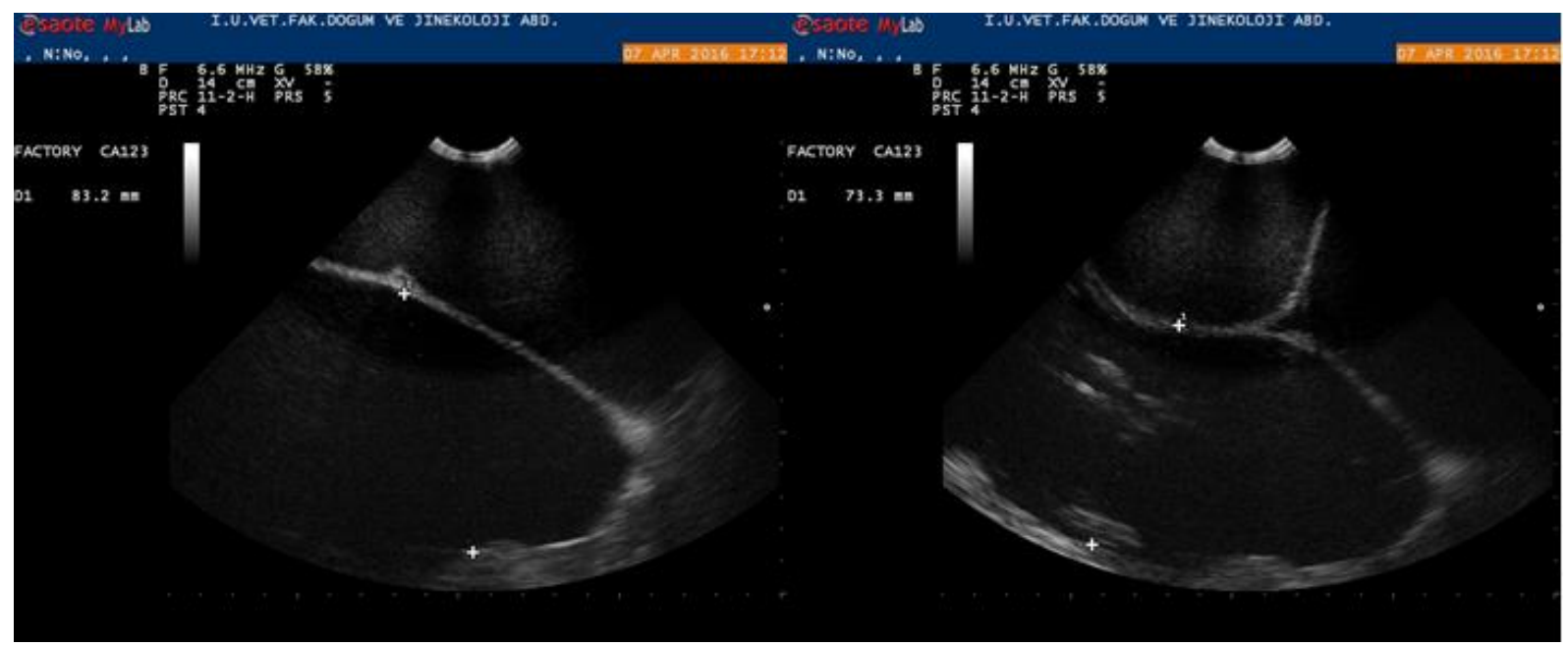

Şekil 2. Kornu uterilerin ultrasonografik görüntüsü.

Kornu uterilerin duvarlarının inceldiği ve lümenlerinin anekojenik olduğu görüntülendi. Bu klinik bulgular eşliğinde CEH-P teşhisi konulan hastaya ovariohisterektomi operasyonu uygulanmasına karar verildi. Bu doğrultuda, genel anestezi öncesi deri altı yolla $0.03 \mathrm{mg} / \mathrm{kg}$ dozunda Atropin sülfat (Biofarma, İstanbul, Türkiye) uygulandı. Premedikasyon amacıyla damar içi yolla $6 \mathrm{mg} / \mathrm{kg}$ dozunda propofol (\%1 Pofol ampul, Dongkok Pharm, Kore) verildi. Doz hesaplaması, tahmini uterus ağırlığı kedinin ameliyat öncesi ağırlığından çıkartılarak yapıldı. İndüksiyonu takiben hasta entübe edilerek, \%3 oranında izofluran likid (Foran likit, Abott Laboratories, Ingiltere) ve \%1 oranında oksijen ile inhalasyon anestezisi sağlandı.
Operasyon sırasında oluşabilecek yan etkilerden (hipovolemik şok vs.) korunmak için izotonik serum infüzyonu yapıldı. Aşırı abdominal genişlemeye sahip bu kedide, aorta abdominalise basınç sonucu dolaşımın engellenmesinin önüne geçmek amacıyla, kedi hafif yan yatırılarak göbek deliğinin gerisinden median enzisyon uygulandı. Aşırı gergin uterusa zarar vermemek için kas dokusuna atılan iki tespit dikişi arasından enzisyon yapılarak, oluklu sonra eşliğinde laparotomi uygulandı. Ovariohisterektomi sonrasında kornu uterilerin ve tüm periton yüzeyinde, basınç atrofisi nedeniyle olduğu düşünülen, difuz dağılımlı, yağ benzeri oluşumlar gözlendi (Şekil 3A,3B). Tüm dikişler ve ligatürler için monoflament iplik (Monocryl No:2/0, Medeks, 
Türkiye) kullanıldı. Ovaryumlar ve uterus $2.4 \mathrm{~kg}$ olarak ölçüldü. Operasyon sonunda uterus içeriğinden örnek alınarak etken izolasyonu ve antibiyogram için i..ü. Veteriner Fakültesi Mikrobiyoloji Anabilim Dalı Laboratuvarı'na gönderildi. Postoperatif destekleyici tedavi olarak hastaya damar içi yolla $40 \mathrm{ml} / \mathrm{kg}$ dozunda $\% 0.9 \mathrm{NaCl}$ izotonik serum (I.E. Ulagay, Türkiye), kas içi 40 $\mathrm{mcg} / \mathrm{kg}$ dozunda B12 vitamini (Dodeks, Deva, Türkiye), kas içi $4 \mathrm{mg} / \mathrm{kg}$ dozunda ranitidin (Ulcuran, Abfar, Türkiye), kas içi $20 \mathrm{mg} / \mathrm{kg}$ dozunda ampisilin/sulbaktam (Sulcid, İ.E. Ulagay, Türkiye), deri altı $5 \mathrm{mg} / \mathrm{kg}$ dozunda enroflaksasin (Baytril-K $\% 5$, Bayer, Almanya), 10 gün süreyle uygulandı. Operasyon sonrası 10.günde dikişleri alınan hastanın genel durumunun iyi olduğu bildirildi.

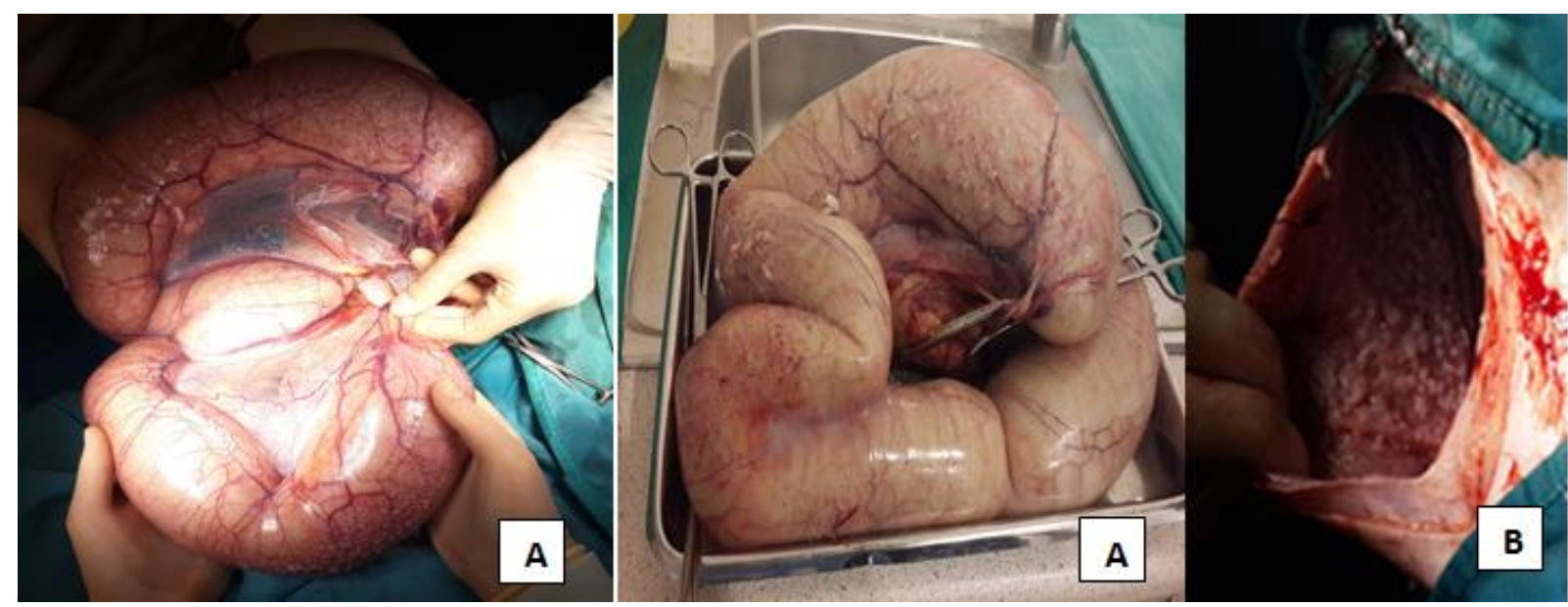

Şekil 3. A. Ovariohisterektomi sonrası kornu uterilerin görüntüsü, B. Periton yüzeyindeki diffuz dağılımlı oluşumlar.

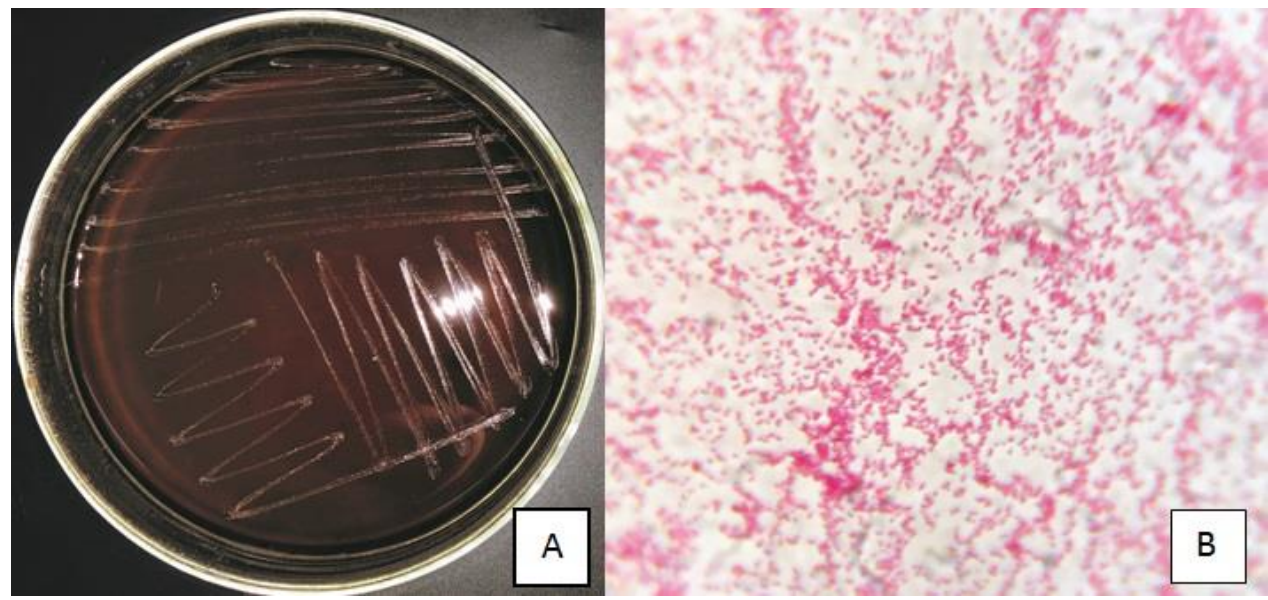

Şekil 4A. Mannheimia haemolytica suşu, B. Mannheimia haemolytica'nın mikroskop görüntüsü.

Uterus içeriğinden \%7 koyun kanlı Agar (CM271- Oxoid) ve Mac Conkey Agar'a (CM0109Oxoid) ekim yapıldı. Agarlar aerobik ve mikroaerofilik şartlarda $37^{\circ} \mathrm{C}^{\prime}$ de 24 saat süreyle inkübe edildi. Kanlı agarlarda hemoliz pozitif, s tipi koloniler üredi. Mac Conkey Agarda ise üreme olmadı. Üreyen kolonilerden yapılan Gram boyama sonucunda Gram negatif basiller görüldü. Standart metodlarla oksidaz, katalaz, indol ve Mc Conkey agarda üreme gibi özellikleri incelenerek ve APi 20 NE (bioMerieux) kullanılarak yapılan identifikasyon sonucunda izolatın Mannheimia haemolytica olduğu belirlendi (Şekil 4A, 4B). İzolatın antibiyotik duyarlılıklarının belirlenmesi, Clinical and
Laboratory Standards Institute (CLSI) standartlarına göre Kirby-Bauer disk difüzyon yöntemi kullanılarak yapıldı (CLSI 2006). Bunun sonucunda izolatın amoksisilin, amoksisilin/klavulanikasid, ampisilin/sulbaktam, enrofloksasin, eritromisin, gentamisin, kloramfenikol, meropenem, sefaleksin, sefaperazon, sefepim, seftiofur, seftriakson, siprofloksasin, streptomisin, tetrasiklin ve trimetoprim/ sülfametoksazol antibiyotiklerine karşı duyarlı olduğu belirlendi. Aztreonam, sefpodoksim, sefoksim/klavulonikasit, seftazidin/klavulonikasit ve seftazidim antibiyotiklerine karşı ise dirençli olduğu saptandı. 


\section{Tartışma}

$\mathrm{Bu}$ olgu sunumunda CEH-P'nın 8 yaşında, kısırlaştırılmamış dişi bir kedide görülmesi hastalığın görülme yaşı açısından literatür bilgi ile uyumludur. Anamnezde kontraseptif kullanımı bulunmamasına karşın orta yaştaki kedilerde de pyometra şekillendiği bilinmektedir (Lucas, 2000). Aşırı genişlemiş abdomenin muayenesinde; ascites, gebelik, pyometra, uterus patolojilerinin ayırıcı tanısının konulması amacıyla radyografi yerine ultrasonografi gibi diagnostik görüntüleme tekniğinin araştırmacılar tarafından tercih edilmesi sunulan vakadaki teşhis metodunu destekler niteliktedir (Hagman, 2017). Operatif müdahale sırasında, ensizyon öncesi pyometra nedeniyle abdomendeki aşırı gerginliğe ve ligatür işlemi esnasında uterusun gevrek oluşuna dikkat edilerek ovariohisterektomi uygulanması Hollinshead ve Krekeler (2016) ile uyumludur. Araştırmacılarla uyumlu olarak (Agudelo, 2005; Sapierzynski ve ark, 2009), sunulan vakada kedilerde nadiren görülen poliüri ve polidipsi gibi üriner sistem semptomlarının şekillenmesine, lipopolisakkarit yapısında hücre duvarına (endotoksin) sahip gram () bakterilerden olan Mannheimia haemoltica'nın neden olduğu düşünülmektedir. Yapılan literatür taraması neticesinde Mannheimia haemoltica'nın sığırlarda nekrotik pneumoninin ve pleuropneumoninin en büyük sebebi (Singh ve ark., 2011) olması, sığırların ve koyunların yanı sıra kedi ve köpeklerin oral kavitesinde, nazofarenksinde ve tonsillerinde doğal olarak bulunan fırsatçı bir patojen (Machino ve ark., 2011), ayrıca koyunlarda meme içi yangısal enfeksiyona neden olan önemli bir bakteri (Omaleki ve ark., 2011) olması, bu bakterinin genellikle respiratörik sistem ve meme üzerine etkili olduğunu göstermektedir. Kedi ve köpeklerdeki pyometra olgularında Mannheimia haemoltica'nın izole edildiğine dair herhangi bir literatür bilgiye rastlamamış olmamız, sunulan vakanın orjinalliğini destekler niteliktedir.

Sonuç olarak, sunulan vakada Mannheimia haemoltica'nın kedilerde pyometra olgularında izole edilebileceği ve sağlıklı bir kedinin canlı ağırlığına yakın boyutlara kadar ulaşabilen uterus görüntüsünün şekillenebileceği vurgulanmaktadır.

\section{Kaynaklar}

Agudelo CF, 2005: Cystic endometrial hyperplasia-pyometra complex in cats. Vet $Q, 27(4)$, 173-182.

Blendinger K, Bostedt $\mathrm{H}$, Hoffmann B, 1997: Hormonal state and effects of the use of an antiprogestin in bitches with pyometra. J Reprod Fertil, 51, 317-325.

Clinical and Laboratory Standards Institute, 2006: Performance Standards for Antimicrobial Susceptibility Testing, Sixteenth Informational Supplement. CLSI document M100-S16 [ISBN 156238-588-7). Clinical and Laboratory Standards Institute, Pennsylvania, USA.

Dinç DA, 2005: Karnivorlarda infertilite. In 'Evcil hayvanlarda doğum ve infertilite.' Ed; Alaçam E, Medisan Yayınevi, Ankara, Türkiye.

Hagman R, 2017: Molecular aspects of uterine diseases in dogs. Reprod Domest Anim, 52(3), 37-42.

Hollinshead F, Krekeler N, 2016: Pyometra in the queen. To spay or not to spay? J Feline Med Surg, 18, 2133.

Holt BS, Bergström A, Lagerstedt AS, Karlstam E, Englund L, Baverud V, 2003: Characterization of the bacterial population genital tract of adult cats. Am J Vet Res, 64, 963-968.

Lucas SS, Lima de Oliveira AL, Wallau JE, 2000: Pyometra in Dogs and Cats: Review of 103 cases. Revista da FZVA Uruguaiana, 7, 99-103.

Machino M, Yukawa $Y$, Ito K, Nakashima H, Kanbara S, Morita D, Kato F, 2011: Pyogenic Cervical Spondylitis Caused by Pasteurella haemolytica Attributed to Excessive Contact With Dogs. Orthopaedics, 34(11), 793-795.

Omaleki L, Browning GF, Allen JL, Barber SR, 2011: The role of Mannheimia species in ovine mastitis. J Vet Mic, 153, 67-72.

Sapierzynski RA, Dolka I, Cywinska A, 2009: Multiple pathologies of feline uterus: a case report. Vet Med, 52, 345-350.

Singh K, Ritchey JW, Confer AW, 2011: Mannheimia haemolytica: Bacterial-host interactions in bovine pneumonia. Vet Pathol, 48(2), 338-348.

Von Reitzeinstein M, Archbald FL, Newell SM, 2000: Theriogenology question of the month. What are the differential diagnoses for uterine enlargement in this unmated cat? Pyometra, hydrometra or mucametra. JAVMA, 216, 1221-1223.

Yazışma adresi: Zeynep GÜNAY UÇMAK

İstanbul Üniversitesi Veteriner Fakültesi, Doğum ve Jinekoloji Anabilim Dalı, Avcılar, İstanbul.

E-mail: vethekzeynep86@gmail.com 